\title{
Concept mapping-An effective method for identifying diversity and congruity in cognitive style
}

Citation for published version (APA):

Stoyanov, S., Jablokow, K., Rosas, S. R., Wopereis, I. G. J. H., \& Kirschner, P. A. (2017). Concept mapping-An effective method for identifying diversity and congruity in cognitive style. Evaluation and Program Planning, 60, 238-244. https://doi.org/10.1016/j.evalprogplan.2016.08.015

DOI:

10.1016/j.evalprogplan.2016.08.015

Document status and date:

Published: 01/02/2017

Document Version:

Early version, also known as pre-print

Document license:

CC BY-NC-SA

Please check the document version of this publication:

- A submitted manuscript is the version of the article upon submission and before peer-review. There can be important differences between the submitted version and the official published version of record. People interested in the research are advised to contact the author for the final version of the publication, or visit the DOI to the publisher's website.

- The final author version and the galley proof are versions of the publication after peer review.

- The final published version features the final layout of the paper including the volume, issue and page numbers.

Link to publication

\section{General rights}

Copyright and moral rights for the publications made accessible in the public portal are retained by the authors and/or other copyright owners and it is a condition of accessing publications that users recognise and abide by the legal requirements associated with these rights.

- Users may download and print one copy of any publication from the public portal for the purpose of private study or research.

- You may not further distribute the material or use it for any profit-making activity or commercial gain

- You may freely distribute the URL identifying the publication in the public portal.

If the publication is distributed under the terms of Article 25fa of the Dutch Copyright Act, indicated by the "Taverne" license above, please follow below link for the End User Agreement:

https://www.ou.nl/taverne-agreement

Take down policy

If you believe that this document breaches copyright please contact us at:

pure-support@ou.nl

providing details and we will investigate your claim.

Downloaded from https://research.ou.nl/ on date: 26 Apr. 2023 
This is a pre-print of:

Stoyanov, S., Jablokow, K., Rosas, S. R., Wopereis, I. G. J. H., \& Kirschner, P. A. (2016). Concept mappingAn effective method for identifying diversity and congruity in cognitive style. Evaluation and Program

Planning. Advance online publication. doi: http://dx.doi.org/10.1016/j.evalprogplan.2016.08.015

\section{Concept mapping - an effective method for identifying diversity and congruity in cognitive}

$$
\text { style }
$$

Slavi Stoyanov ${ }^{1}$, Kathryn Jablokow ${ }^{2}$, Scott, Rosas ${ }^{3}$, Iwan Wopereis ${ }^{1}$, Paul Kirschner ${ }^{1}$

${ }^{1}$ Open University of the Netherlands,

${ }^{2}$ Pennsylvania State University

${ }^{3}$ Concept System, Inc 


\begin{abstract}
This paper investigates the effects of cognitive style for decision making on the behavior of participants in different phases of the group concept mapping process (GCM). It is argued that cognitive style should be included directly in the coordination of the GCM process and not simply considered as yet another demographic variable. The cognitive styles were identified using the Kirton Adaption-Innovation Inventory, which locates each person's style on a continuum ranging from very adaptive to very innovative. Cognitive style could explain diversity in the participants' behavior in different phases of the GCM process. At the same time, the concept map as a group's common cognitive construct can consolidate individual differences and serves as a tool for managing diversity in groups of participants. Some of the results were that: (a) the more adaptive participants generated ideas that fit to a particular, well-established and consensually agreed paradigm, frame of reference, theory or practice; (b) the more innovative participants produced ideas that were more general in scope and required changing a settled structure (paradigm, frame of reference, theory or practice); and (c) the empirical comparison of the map configurations through Procrustes analysis indicated a strong dissimilarity between cognitive styles.
\end{abstract}




\section{Introduction}

A distinguished feature of the Group Concept Mapping (GCM) method when compared to other similar methods (e.g., Affinity diagrams or Delphi) is that it shows in an objective way the shared vision of a group of experts on a particular issue. The methodology can also identify and compare participants on some individual characteristics, such as level of expertise, professional experience, educational background, job role, and gender, to mention but a few. The comparison of these individual differences is typically shown by GCM pattern matches and less often by subgroups' concept maps. It is claimed that this type of analysis provides additional insight into the data, which is often considered secondary, although this is not always acknowledged explicitly. Cognitive style is an individual difference characteristic whose role in the GCM process, to the best of our knowledge, has not yet been explored. Cognitive style refers to individual differences in people's preferred way of perceiving, organising and analysing information, and in particular, differences in how people manage structure as part of these cognitive activities.

There are at least three reasons why cognitive style should be included directly in the coordination of the GCM process and not simply considered as yet another demographic variable along with level of expertise, professional experience, educational background, job role, or gender. Firstly, cognitive style operates across all these individual differences. For example, both highly innovative and highly adaptive cognitive styles can be found at similar levels of expertise, professional experience, job roles, educational background, and for both genders. Secondly, cognitive style appears to have an impact on most of the phases of the GCM process. Differences in cognitive style can be observed in the types of statements generated, point map configurations, pattern matches and in suggestions made during the interpretation of the GCM outcomes. Thirdly, evidence-based cognitive style theories can predict individual behaviour, explain the 
reasons for differences in the behaviour of people, and suggest measures for managing diversity in groups.

It has been shown that cognitive diversity has a greater impact on decision-making than demographic diversity (Jehn, Northcraft, \& Neale, 1999; Williams \& O’Railly, 1998). Likewise, cognitive style diversity is assumed to be a better predictor of team performance than traditional demographic variables (Miller, Burke, \& Glick, 1998; Schilpzand \& Martins, 2010).

At the same time, the concept map as a common, whole group, cognitive construct can consolidate individual differences and serves as a tool for managing diversity in groups of participants. It represents the shared cognition of the group (Salomon, 1997; Stahl, 2006; Van den Bossche, Gijselaers, Segers, Woltjer, \& Kirschner, 2011). In this paper, we combine two research paradigms - (a) cognitive style, and (b) group concept mapping - to demonstrate how they could lead to mutually beneficial insights. The cognitive style paradigm can contribute to predicting the behaviour of participants in different phases of the GCM process and to explaining differences in the participants' concept maps and pattern matches based on their cognitive styles. The GCM paradigm can first help us visualize individual differences in concept maps and then show how they can be consolidated in the whole group concept map. As a common, objectively identified, cognitive artefact, a group concept map can serve as a tool for managing diversity in cognitive style in addition to the ways proposed in the cognitive style paradigm. Based on findings reported in the literature on cognitive style and outcomes within the framework of a case study, this paper proposes a set of hypotheses that could guide future research on the role of cognitive style in the GCM process.

In the remaining sections of this paper, we first briefly review research on cognitive style to provide context for associating particular cognitive styles with different types of problem solving and decision making. Then we explore differences in the cognitive styles of the 
participants and show how these differences could be mutually beneficial for each other as observed in the outcomes of a GCM project. Finally, we discuss the results of the case study, formulate some conclusions, and make suggestions for future work.

\section{Cognitive style - definitions and implications for the GCM process}

Cognitive style refers to a psychological dimension that represents consistencies in an individual's manner of cognitive functioning, particularly with respect to perceiving, remembering, thinking, decision making and problem solving. Cognitive styles are assumed to be relatively stable over time; they are value free, possibly innate, and related to personality (Armstrong, Peterson, \& Rayner, 2011; Kirton, 2006).

Some examples of cognitive style dimensions are as follows: 'field dependence-field independence’ (Witkin at al., 1962); 'reflective-impulsive’ (Kagan, 1966); 'serialist-holist’ (Pask \& Scott, 1972); 'converger-diverger' (Hudson, 1968); 'simultaneous-successive’ (Das, 1988); ‘wholist-analytic’ (Riding \& Buckle, 1990), and ‘adaption-innovation’ (Kirton, 2006), to name a few. For a detailed overview and classification of cognitive style, see also Riding and Cheema (1991), Jonassen and Grabowski (1993), Rayner and Riding (1997), and Zhang, Sternberg, and Rayner (2012).

In addition to its impact at an individual level, cognitive style can affect the way teams function as well. Teams engaged in complex decision-making need to consider their task from different perspectives, thus increasing the likelihood that all relevant information is included, which results in better coverage of the task problem space (Hambrick, Cho, \& Chen, 1996; Schilpzand \& Martins, 2010; Williams \& O’Reilly, 1998).

Of particular interest to the objectives of this study are the cognitive style constructs defined in the context of problem-solving and decision making, such as those measured by the Myers-Briggs Type Indicator (MBTI; Myers \& McCaulley, 1985; Myers \& Myers, 1995) and the 
Kirton Adaption-Innovation Inventory (KAI; Kirton, 2006), which are frequently referred to and used in research and practice (Armstrong, Cools, \& Sadler-Smith, 2012; Franco, Meadows, \& Armstrong, 2013). The Myers-Briggs Type Indicator (MBTI) has been used extensively as a cognitive style instrument, but it was not developed to measure exclusively cognitive styles; it identifies personality types. Specifically, the four basic dimensions of MBTI (i.e., sensingintuition, thinking-feeling, judging-perceiving, and extraversion-introversion) produce 16 personality types when used in combination, which makes MBTI difficult to apply practically in the context of the GCM process. MBTI also associates personality types with particular professional occupations. Cognitive style research indicates, however, that within a profession, different cognitive styles will be present (Kirton, 1999, 2006). It has also been discovered that some of the MBTI items are related to capabilities (i.e., level-based constructs), not preferences (i.e., style-based constructs) (Kirton, 1999).

$\mathrm{KAI}$ is a pure stylistic measure, it is much simpler to use, and it is highly regarded. KAI is based on well-established theory that has been used in different academic and business domains for more than 40 years. Equally important, it has strong predictive power, high reliability, and extensive validity evidence. We turn now to a more detailed discussion of its underlying theory and applications.

\section{Some evidence-based facts about Adaption-Innovation theory}

Kirton’s Adaption-Innovation (A-I) theory makes a strong distinction between style constructs and level constructs, including both potential level (e.g., intelligence and cognitive complexity) and manifest level (e.g., knowledge, competencies, or experience). Style and level do not correlate, as has been established in the literature (Kirton, 2006). A-I theory also distinguishes between style and observed behaviour. Style is stable over time, while behaviour is flexible when circumstances require it, resulting in coping behaviour. There is also a distinction 
made in A-I theory between style and process. A process (like GCM process) is an ideal template or roadmap for how we move through our problem solving. No stage in a process is associated with a particular style; instead, different cognitive styles can operate in each phase.

As a measure of cognitive style, the KAI Inventory locates people on a continuum that ranges from highly adaptive to highly innovative, with large general populations exhibiting normal distributions. Because cognitive style is stable, the KAI score people receive does not change over time; however, as individuals, they may fall on the more innovative or the more adaptive side of a particular group, depending on that group’s overall style distribution.

In general, the more adaptive one is, the more one has a positive regard for structure (e.g., theory, guidelines, policy) and consensus, and the more one will prefer to problem solve by defining, refining, extending, and improving the current, generally accepted pattern, strategy, or paradigm. That is, the more adaptive tend to make things 'better'. In contrast, the more innovative one is, the less tolerant one is of existing structure and the less respect one has for consensus; that is, the more innovative tend to do things 'differently'. The more adaptive also tend to produce or offer a relative few sound and practical ideas within the borders of a particular paradigm, while the more innovative tend to generate many ideas as they try to work to the edges of (or even outside of) a well-established paradigm - possibly combining different paradigms. As befits a continuum, it is better to say "more adaptive" and "more innovative” when describing individuals, although the terms "adaptor" and "innovator" are sometimes used for convenience.

The more cognitive style diversity present in a problem solving team, the wider the range of problems that the group can tackle, but the more difficult it is to manage. The less cognitive style diversity, the more limited the range of problems the group can tackle effectively, but the easier it is to manage. Awareness of style diversity is the first step in learning to become more tolerant and appreciative of its value in problem solving. 


\section{Group Concept Mapping outcomes findings}

In this section, we discuss three hypothetical propositions with regard to AdaptionInnovation (A-I) style differences in GCM outcomes using the data of one GCM project. Here are our assumptions based on A-I theory:

1. Individuals with different cognitive styles will generate different types of statements. The participants with more innovative styles will more often produce statements that require changing a well-established structure (paradigm, frame of reference, theory or practice). The more adaptive participants will formulate statements that fit to a well-defined and consensually agreed structure (paradigm, reference, theory or practice).

2. As more innovative individuals tend to sort together concepts that represent different domains, we expect their concept maps to have a more widely dispersed configuration than those of the more adaptive participants. We expect a low resemblance between the maps of those with different cognitive styles.

3. There will be a low correlation between the clusters' ratings of the more innovative and more adaptive participants as presented in pattern match ratings.

\section{Method}

The basic research method we will employ is an exploratory case study (Yin, 1994), including a secondary analysis of the GCM data. The case study concerns expertise decomposition of musical improvisation (Wopereis, Stoyanov, Kirschner, \& Van Merriënboer, 2013). The Kirton Adaption-Innovation Inventory (KAI) was administered to measure cognitive style, but the results have not been discussed nor published elsewhere. We applied a qualitative analysis to the type of statements generated. For comparing the cognitive style maps, we attempted a method (Hammarlund, Nilson, Idvall, Rosas, \& Hagell, 2014) that integrates measures of internal 
representation validity of concept maps and the degree of resemblance of the map configurations through Procrustes analysis (Peres-Neto \& Jackson, 2001). We set out to test the correspondence between the structural representations of the two groups (Adaptors vs. Innovators) by conducting a multivariate rotational-fit algorithm between two configurations as represented by the two sets of $\mathrm{x}-\mathrm{y}$ coordinates for each respective map (2 dimensional, multivariate summaries). In conducting these analyses, we sought to determine how much these configurations resembled each other. Data were analysed separately for Innovators and Adaptors using the Concept Systems Core ${ }^{\circledR}$ software (2014), PROTEST software (Jackson, 2015) and IBM SPPS software (version 20, 2011). The Procrustes analysis is an improvement of the Mantel test (Mantel, 1967), which is becoming a popular measure of the association between distance matrices. It has been found that the Procrustes analysis is more sensitive to type I error rates and to power of significance tests compared to the Mantel test (Peres-Neto \& Jackson, 2001; Schneider \& Borlund, 2007). There are two additional features of the Procrustes analysis that make it more appropriate for the case study considered in this paper. First, the Procrustes technique produces a numerical measure of the resemblance of two configurations for the same set of objects (each object in one data set corresponds directly to an object of the other data set). Second, the Procrustes analysis can deal with non-linear models and not-normal distributions of the samples, which is an advantage in our case.

Given the two configurations are of the same multivariate observations, the difference between the two configurations was therefore measured by aggregating the distance between their corresponding points. To account for the lack of independence among distances and the spuriousness of their correlation, Procrustes analyses were used to minimize the sum of squared deviations between the data values in two observation-by-variable matrices through matrix translation, reflection, rigid rotation and dilation (Jackson, 1995; Peres-Neto \& Jackson, 2001). 
The residuals from the configurations are used to determine the best fit solution, which generates a metric of association. A goodness-of-fit statistic called $\mathrm{m}^{2}$ is produced (Gower, 1971, cited in Schneider \& Boland, 2007). The lower the Procrustes statistic, the closer the resemblance between the two configurations. To evaluate the significance of the observed $\mathrm{m}^{2}$ statistic, 10,000 random permutations were run to estimate the probability of the derived statistic and ensure the relative stability of the estimated p-value (Jackson, 1995). Type I error rates are estimated as the proportion of sample tests out of the number of permutations that reject the null hypothesis. The power of the test is the proportion of sample tests that correctly detect true association, i.e., the fit is better than expected by chance.

Cognitive style measurement instrument

Apart from the statements generated, observation notes, and interview transcripts of cognitive style feedback, the main measurement instrument for the case study is the KAI Inventory, which is the principal validation instrument for A-I theory (Kirton, 1978, 2006).

The KAI Inventory contains 32 items, which are scored using a 1-5 scale; the observed scores fall between 45 and 145, with a mean of 95 (SD = 17). The instrument has been validated using 10 large, general population samples with more than 3000 people overall. KAI’s internal reliability ranges from 0.84 to 0.89 (mode $=0.87$ ). No social desirability or cultural effects have been found to date. As expected from theory, the KAI Inventory correlates strongly with other style measures but not with level measures (e.g., intelligence, cognitive complexity, attainment). It is out of the scope of the current study to provide a detailed report on the psychometric studies that have been used to validate the KAI inventory. The interested reader can find detailed information in Kirton’s work (1999; 2006).

In terms of individual scores, a cognitive gap of 10 points between problem solvers on the Adaption-Innovation (A-I) continuum signifies the "just noticeable difference" for KAI, 
irrespective of where the two individuals fall on the scale - i.e., between a more innovative person and a more adaptive person or between two people on the same side of the mean. Larger cognitive gaps are notable for multiple reasons: 20-point gaps indicate “clear noticeable differences” between individuals, while gaps of 30-40 points (or more) could be a source of conflict and require particular care (Kirton, 1999, p. 18; p. 84).

In the next section, we briefly describe a case study, within the framework of which we provide some evidence with regard to the assumptions stated earlier.

\section{An expert view on musical improvisation expertise. A case study}

The case study was aimed at identifying and prioritizing the knowledge, skills and attitudes of an expert musical improviser. The results of the study were to inform the design of training in improvisation (for more details, see Wopereis et al., 2013). The GCM procedure included the general phases as described by Trochim and McLinden (this issue) with face-to-face idea generation and manual card sorting and rating. Twenty minutes of the face-to-face meetings were devoted to filling out the KAI Inventory. The administration of KAI served two purposes: (a) as a means of capturing the effect of cognitive style on idea generation and structuring; and (b) as an incentive for participation (every participant received individual feedback based on his or her KAI score).

\section{Study participants}

A total of 26 musical experts from the Netherlands took part in the study. The experts had more than 20 years of professional experience in performing and teaching, and about 20 years reviewing jazz and contemporary improvised music. The mean age of the experts was about 50 years. Sixteen experts contributed to the idea generation; 14 of them participated in the sorting and rating. All but one of the participants were men; 14 of the participants filled out the KAI. 
Half of these $14(\mathrm{n}=7)$ had more innovative cognitive styles relative to the mean of the group (M $=108.5$; SD =10.2), while the other half had more adaptive styles relative to this mean.

The sixteen experts generated 191 statements in completing the following focus prompt: “A good improviser is someone who...” After data cleaning and editing, 169 ideas were left for sorting and rating. The stress index for this project was 0.34 , which is in the accepted range as suggested by the literature (Kane \& Trochim, 2007; Rosas \& Kane, 2012; Trochim, 1989). Results

\section{Distribution of the KAI scores}

The KAI scores ranged from 88 (very adaptive style) to 125 (very innovative style) with a mean of $\mathrm{M}=108.5$ ( $\mathrm{SD}=10.2)$. The gap between the most innovative and the most adaptive scores is almost 40 points.

\section{Types of statements generated}

Some examples of statements generated by the more innovative participants are: ‘... who understands that not playing is also playing', ' . . . who is able to play nothing when he hears nothing', '. . . who dares taking risks and who is adventurous, but not reckless', ‘. . whowhether or not starting from existing material—creates new music that is both comprehensible and surprising, both reassuring and disturbing', '. . . who spontaneously thinks of and tells a coherent story', '... who is not afraid of making mistakes', ‘. . who dares to fall flat on his face’, ‘. .. who draws musical connections quickly', and '... who is not concerned with public expectation'.

Example statements generated by the more adaptive participants are: ‘...someone with musical mastery', ‘ . . . who makes use of the possibilities of his instrument', ‘ . . with a passion for music', '... someone who is able to organize musical thoughts, ideas on the spot, '... someone who brings order to chaos', ‘... with a highly developed sense of rhythm', ... . who always puts 
the music first, not his ego’, ‘... who does not consider frameworks limiting, but uses/misuses them for new forms and thoughts', and '... who has very good ears and listens with them'.

These examples show that the more innovative and the more adaptive see improvisation in different ways. The key words for the more adaptive relate to mastery of the instrument, passion for music, order, organization, sense of rhythm, and using a framework. The key words used by the more innovative relate to taking risks, not being afraid of making mistakes, creating new music, spontaneous, telling a story with the music, and drawing inspiration from different kinds of music. These descriptions of more innovative and more adaptive preferences for performing musical improvisation are in line with Adaption-Innovation (A-I) theory and confirm our assumption about the type of statements generated.

\section{Resemblance of maps' structural representations}

For this case study, the MDS analysis of the sorting data resulted in 2-dimensional maps with stress values of 0.29 for Adaptors and 0.37 for Innovators (see Figure 1).

\section{****INSERT FIGURE 1 ABOUT HERE****}

The stress value of the Adaptors' map was within the accepted range, and the stress value for the Innovators was slightly above the range found in previous meta-analytic studies of concept mapping (Rosas \& Kane, 2012; Trochim, 1993). The configural similarity correlation between sort and distance matrices for Adaptors was $0.68(p<0.001)$ and $0.49(p<0.001)$ for Innovators, respectively. Both were within the range found in studies of similarly constructed concept maps (Rosas \& Kane; Trochim), but they differed $(z=2.89 ; p=.0019$ following Fisher's r-to-z transformation). The Adaptors' configural similarity correlation was near the upper end of 
the range (relatively stronger relationship between sort and distance data), whereas the Innovators' configural similarity correlation was near the lower end of the range (relatively weaker relationship between sort and distance data). The correlation between the raw sorting data (total similarity matrices) of Adaptors and Innovators was $0.53(p<0.001)$. The spatial arrangement of the Adaptors' map configuration showed slight similarity to the configuration of the Innovators. The match of the two data configurations was greater than expected due to chance $\left(\mathrm{m}^{2}=0.94 ; p<0.001\right)$. Thus, a highly significant concordance between the multivariate data sets was detected, and the two matrices showed a slight non-random resemblance (Schneider \& Boland, 2007). Given that $\mathrm{m}^{2}=1-r^{2}$, we solved for $\mathrm{r}(0.94=1-0.06)$ and found $r$ to be 0.24 . We then compared the magnitude of agreement for the sorting arrangement $(r=0.53 ; n=14,197)$ and the magnitude of the spatial arrangement $(r=0.24 ; n=169)$ and found that they differed $(z=$ 3.27, $p=.0005$, following Fisher's $r$-to-z transformation). These results confirm our expectations for a low resemblance between the different cognitive styles’ map configurations.

\section{Pattern match correlation}

The pattern match indicates high Pearson product-moment correlation between the more adaptive and the more innovative participants $(r=.76)$, which contradicts our initial assumption (see Figure 2).

****INSERT FIGURE 2 ABOUT HERE****

\section{Discussion and conclusions}

The results from the case study are in line with KAI findings about cognitive style differences in participants’ idea generation (Kirton, 2006; Jablokow \& Booth, 2006) and map structural representations. 
The idea generation phase of the GCM process is quite similar to any other idea generation activity, which makes the prediction of the preferred idea generation behaviour of more innovative and more adaptive individuals quite accurate. As a rule, the more innovative reflect more tangential problem solving or decision making perspectives than the more adaptive. In contrast, the more adaptive generate ideas with a more focused perspective but those ideas are more sound and practical. The more adaptive prefer to problem solve and make decisions from within a well-established and consensually agreed structure (e.g., theory or policy), whereas the more innovative prefer to work on the edges of a structure or to combine different structures. This was clearly evidenced by the types of statements generated by more innovative and more adaptive participants.

Quantitatively, we found consistency in the within-group relationship between the sort data and the distance data among items on the maps. There was a strong correspondence for the more adaptive participants; that is, we found a lower stress value and higher configural similarity in our examination of their sort and distance data. Greater variability was found in the relationship between sort and distance data for the more innovative participants, where we observed higher stress and lower configural similarity. There was a low similarity in the map configurations of the different cognitive styles.

The outcomes concerning correlations between different cognitive styles as represented by the pattern match do not support our assumption for a low correlation between the cognitive styles. One possible explanation would be that the rating data are actually measuring level rather than style constructs. That is, even when the participants face 'not preferred' statements, they still rate them high on importance.

A-I theory states that simply being aware of differences in cognitive style is immediately helpful for managing diversity in groups. In addition, "bridgers” (in A-I terms - i.e., team 
members with intermediate scores relative to the current team profile) could help in managing the cognitive gaps in groups, provided these team members are motivated to do so and have the skills required. GCM contributes to managing cognitive diversity in groups by showing in an objective way not only how team members are different (individual cognitive style maps), but also by showing how cognitive styles can be complementary to each other. Given similar levels of expertise, the degree of resemblance of map configurations could be an indication for an array of cognitive styles. The idea of looking at the maps of more adaptive and more innovative participants is not only to show differences between the cognitive styles, but mostly to get insights into constructing a better understanding of their consolidated map. The concept map that integrates the input from more adaptive and more innovative participants is a common cognitive artefact of both cognitive style groups. It demonstrates how different styles can be mutually beneficial to each other, reflecting a richer cognitive reality.

Concept maps are external representations of cognitive structures and processes involved in problem solving and decision making (Stoyanov \& Kommers, 2006). In the classical concept mapping paradigm, these are the mental models of an individual, who constructs the concept map her/himself in a subjective way. A classical concept map created by a group of people portrays the group's thinking, yet it is done in a subjective way as well, and the team's shared vision could be jeopardised if there are huge gaps among the cognitive styles of the participants. Group concept mapping depicts, in an objective way, the shared (distributed) cognition of the group involved in the process.

In our observations, we found that cognitive style can be used to predict the behaviour of not only participants but also of facilitators of the GCM process, specifically in idea synthesis, selection of the number of clusters, and interpretation of the data. This is a topic for further exploration. 
The reader may get the impression that the current paper discusses cognitive style mainly as a predictor of the group concept mapping outcomes. However, we would like to emphasize that a group concept map can disclose differences among the cognitive styles of the participants. A map configuration, widely dispersed could suggest that there is a gap between cognitive styles. In addition, managing diversity in a group through the concept map as a common cognitive artefact is at least as effective as the awareness of differences in cognitive style. We believe that the research on GCM could contribute not only to the cognitive style theoretical framework (KAI theory in particular), but also to a more fundamental discussion on the relationship between individual and shared (distributed) cognition (Salomon, 1997; Stahl, 2006, Van den Bossche, Gijselaers, Segers, Woltjer, \& Kirschner, 2011). Our understanding is that it is not an either-or distinction. GCM is a demonstration not only of the existence of both - individual and distributed cognition - but it is also an illustration of their close relationship.

Although this study tried to outline roughly the contour of a hypothetical framework that would guide the research on and practice of cognitive style in the GCM process, the propositions made should be considered with caution. They were based on only one case study, and the sample was rather small and skewed in terms of the KAI scores. Although these limitations were present here, there were some indications that cognitive style plays an important role in the GCM process. These observations should encourage further exploration of the subject, perhaps utilizing new types of analysis, such as functional network analysis (Goldman \& Kane, 2014), social network analysis (McLinden, 2013) and strategic consensus maps (Tarakci, Ates, Porck, van Knippenberg Groenen, \& de Haas, 2013).

\section{References}


Armstrong, S. J., Peterson, E. R., \& Rayner, S. G. (2011). Understanding and defining cognitive style and learning style: A Delphi study in the context of educational psychology. Educational Studies, 38, 449-455. doi:10.1080/03055698.2011.643110

Armstrong, S. J., Cools, E., \& Sadler-Smith, E. (2012). Role of cognitive styles in business and management: Reviewing 40 years of research. International Journal of Management Reviews, 14, 238-262. doi:10.1111/j.1468-2370.2011.00315.x

Concept System Core (Version 4.0.175) [Computer Software]. Ithaca, NY: Concept Systems, Inc., 2014. Available from www.conceptsystems.com.

Das, J. (1988). Implications for school learning. In R. Schmeck (Ed.), Learning strategies and learning styles (pp.101-129). New York, NY: Plenum.

Franco, L. A., Meadows, M., \& Armstrong, S. J. (2013). Exploring individual differences in scenario planning workshops: A cognitive style framework. Technological Forecasting \& Social Change, 80, 723-734. doi:10.1016/j.techfore.2012.02.008

Goldman, A. W., \& Kane, M. (2014). Concept mapping and network analysis: An analytic approach to measure ties among constructs. Evaluation and Program Planning, 47, 9-17. doi:10.1016/j.evalprogplan.2014.06.005

Gower, J. C. (1971). Statistical methods for comparing different multivariate analyses of the same data. In J. R. Hodson, D. G. Kendall \& P. Tautu (Eds.), Mathematics in the Archaeological and Historical Sciences (pp. 138-149). Edinburgh: Edinburgh University Press.

Hambrick, D. C., Cho, Th. S., \& Chen, M. J. (1996). The influence of top management team heterogeneity on firms' competitive moves. Administrative Science Quarterly, 41, 659684. doi:10.2307/2393871 
Hammarlund, K., S., Nilsson, M., H., Idvall, M., Scott, R., \& Hagell, P. (2014). Conceptualizing and prioritizing clinical trial outcomes from the perspectives of people with Parkinson's disease versus health care professionals: a concept mapping study. Quality of Life Research, 23, 1687-1700. doi:10.1007/s11136-013-0614-3

Hudson, L. (1968). Frames of mind: ability perception and self-perception in the arts and sciences. London: Methuen.

IBM SPSS (Version 20) [Computer Software]. Armonk, NY: IBM Corp., 2011.

Jablokow, K. W., \& Booth, D. E. (2006). The impact and management of cognitive gap in high performance product development organizations. Journal of Engineering and Technology Management, 23, 313-336. doi:10.1016/j.jengtecman.2006.08.003

Jackson, D. A. (1995). PROTEST: A PROcrustean randomization TEST of community environment concordance. Ecoscience, 2(3), 297-303. doi:10.1080/11956860.1995.11682297

Jackson, D. A. (2015). PROTEST [Software]. Available from http://jackson.eeb.utoronto.ca Jehn, K., A., Northcraft, G., B., \& Neale, M., A. (1999). Why differences make a difference: A field study of diversity, conflict, and performance in workgroups. Administrative Science Quarterly, 44, 741-763. doi:10.2307/2667054

Jonassen, D.H., \& Grabowski, B.L. (1993). Handbook of individual differences, learning and instruction. Hillsdale, NJ: Lawrence Erlbaum.

Kagan, J. (1966). Reflection-impulsivity: The generality and dynamics of conceptual tempo. Journal of Abnormal Psychology, 71, 17-24. doi:10.1037/h0022886

Kirton, M. J. (1978). Field dependence and adaption-innovation theories. Perceptual and Motor Skills, 47, 1239-1245. doi:10.2466/pms.1978.47.3f.1239 
Kirton, M. J. (1999). Kirton Adaption-Innovation Inventory. Manual (3rd edition). Berkhamsted, UK: Occupational Research Centre.

Kirton, M. J. (2006). Adaption-Innovation in the context of diversity and change. London: Routledge.

Mantel, N. (1967). A technique of disease clustering and a generalized regression approach. Cancer Research, 27, 209-220.

McLinden, D. (2013). Concept maps as network data: Analysis of a concept map using the methods of social network analysis. Evaluation and Program Planning, 36, 40-48. doi:10.1016/j.evalprogplan.2012.05.001

Miller, C. C., Burke, L. M., \& Glick, W. H. (1998). Cognitive diversity among upper-echelon executives: implications for strategic decision process. Strategic Management Journal, 19, 39-58. doi:10.1002/(SICI)1097-0266(199801)19:1<39::AID-SMJ932>3.0.CO;2-A

Myers, I. B., \& McCaulley, M. H. (1985). A Guide to the development and use of the MyersBriggs Type Indicator. Manual. Palo Alto, CA: Consulting Psychologists Press.

Myers, I. B., \& Myers, P. B. (1995). Gifts differing: Understanding personality type. Palo Alto, CA: Davies-Black Publishing.

Pask, G., \& Scott, B. (1972). Learning strategies and individual competence. International Journal of Man-Machine Studies, 4, 217-253. doi:10.1016/S0020-7373(72)80004-X

Peres-Neto, P. R., \& Jackson, D. A. (2001). How well do multivariate data sets match? The advantages of a Procrustean superimposition approach over the Mantel test. Oecologia, 129, 169-178. doi: 10.1007/s004420100720

Rayner, S., \& Riding, R. (1997). Towards a categorization of cognitive styles and learning styles. Educational Psychology, 17, 5-27. doi:10.1080/0144341970170101 
Riding, R., \& Buckle, C. (1990). Learning styles and training performance. Sheffield, UK: Training Agency.

Riding, R., \& Cheema, I. (1991). Cognitive styles: An overview and integration. Educational Psychology, 11, 193-216. doi:10.1080/0144341910110301

Rosas, S. R., \& Kane, M. (2012). Quality and rigor of the concept mapping methodology: a pooled study analysis. Evaluation and Program Planning, 35, 236-245 doi:10.1016/j.evalprogplan.2011.10.003

Salomon, G. (Ed.).(1997). Distributed cognition. Cambridge, UK: Cambridge University Press. Schilpzand, M. C., \& Martins, L. L. (2010). Cognitive diversity and team performance: The roles of team mental models and information processing. Academy of Management Proceedings, 1, 1-6. doi:10.5465/AMBPP.2010.54484962

Schneider, J. W., \& Borlund, P. (2007). Matrix comparison, part 2: Measuring the resemblance between proximity measures or ordination results by use of the Mantel and Procrustes statistics. Journal of the American Society for Information Science and Technology, 58(11), 1596-1609. doi:10.1002/asi.20642

Stahl, G. (2006). Group cognition: Computer support for building collaborative knowledge. Cambridge, MA: MIT Press.

Stoyanov, S., \& Kommers, P. (2006). WWW-intensive concept mapping for metacognition in solving ill-structured problems. International Journal of Continuing Engineering Education and Lifelong Learning, 16,3/4, 297-316. doi:10.1504/IJCEELL.2006.009205

Tarakci, M., Ates, N. Y., Porck, J. P., van Knippenberg, D., Groenen, P. J. F., \& de Haas, M. (2013). Strategic consensus mapping: A new method for testing and visualizing strategic consensus within and between teams. Strategic Management Journal, 35, 1053-1069. doi:10.1002/smj.2151 
Trochim, W. M. K. (1989). An introduction to concept mapping for planning and evaluation. Evaluation and Program Planning 12, 1-16. doi:10.1016/0149-7189(89)90016-5

Trochim, W. M. K. (1993). The reliability of concept mapping. Paper presented at the annual conference of the American Evaluation Association, Dallas, TX, November 6, 1993.

Van den Bossche, P., Gijselaers, W., Segers, M., Woltjer, G., \& Kirschner, P. (2011). Team learning: building shared mental models. Instructional Science, 39, 283-30. doi:10.1007/s11251-010-9128-3.

Williams, K. Y, \& O’Railly, Ch. A. (1998). Demography and diversity in organisations. A review of 40 years of research. In B. M. Staw \& R. M. Sutton (Eds.), Research in organizational behavior (pp. 77-140). Greenwich, CT: JAI Press.

Witkin, H., Dyk, R., Faterson, H., Goodenough, D., \& Karp, C. (1962). Psychological differentiation: Studies of development. London: John Wiley and Sons.

Wopereis, I. G. J. H., Stoyanov, S., Kirschner, P. A., \& Van Merriënboer, J. J. G. (2013). What makes a good musical improviser? An expert view on improvisational expertise. Psychomusicology: Music, Mind, and Brain, 23, 222-235. doi:10.1037/pmu0000021 Yin, R. K. (1994). Case study research: Design and methods (2nd edition). London: SAGE. Zhang, L.-F., Sternberg, R.J., \& Rayner, S. (Eds.). (2012). Handbook of intellectual styles: Preferences in cognition, learning and thinking. New York, NY: Springer. 


\section{Figure Captions}

Figure 1. Point maps for more innovative and more adaptive participants

Figure 2. Pattern match: more innovative vs more adaptive participants 
Figure 1. Point maps for more innovative and more adaptive participants

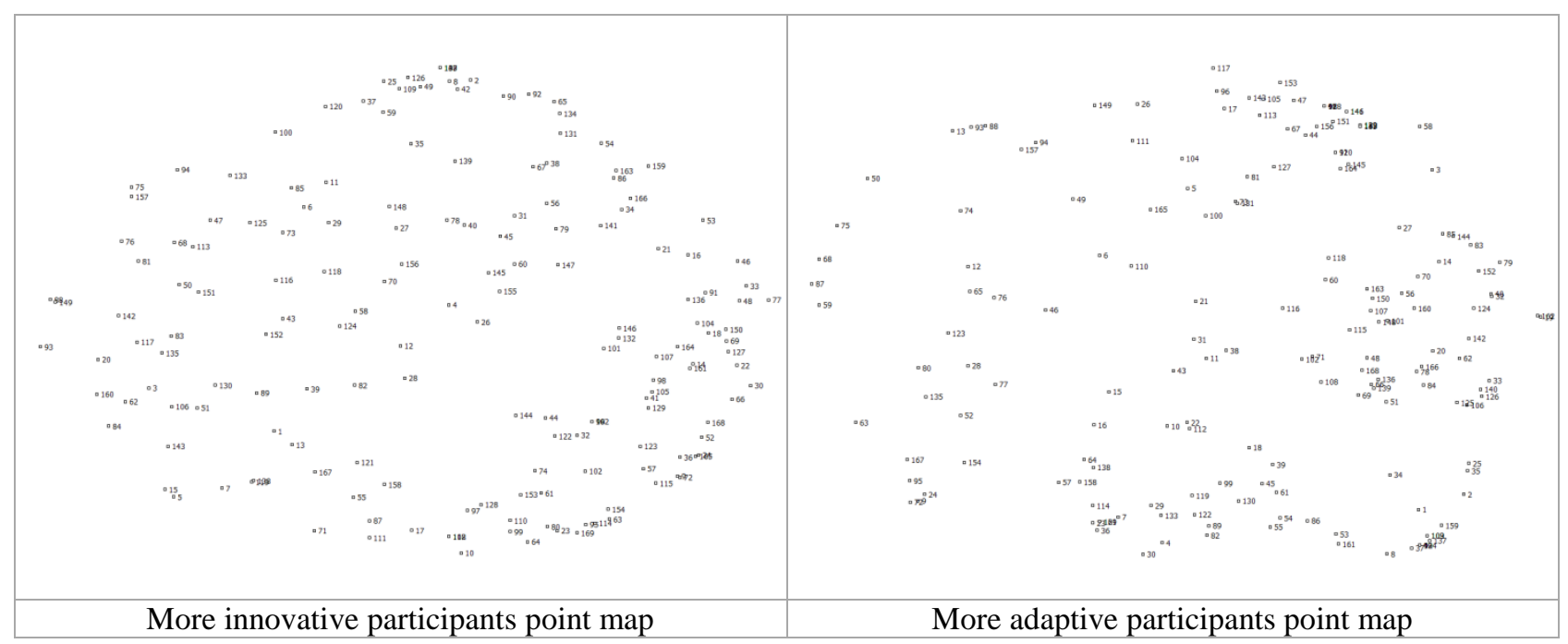


Figure 2. Pattern match: more innovative vs more adaptive participants

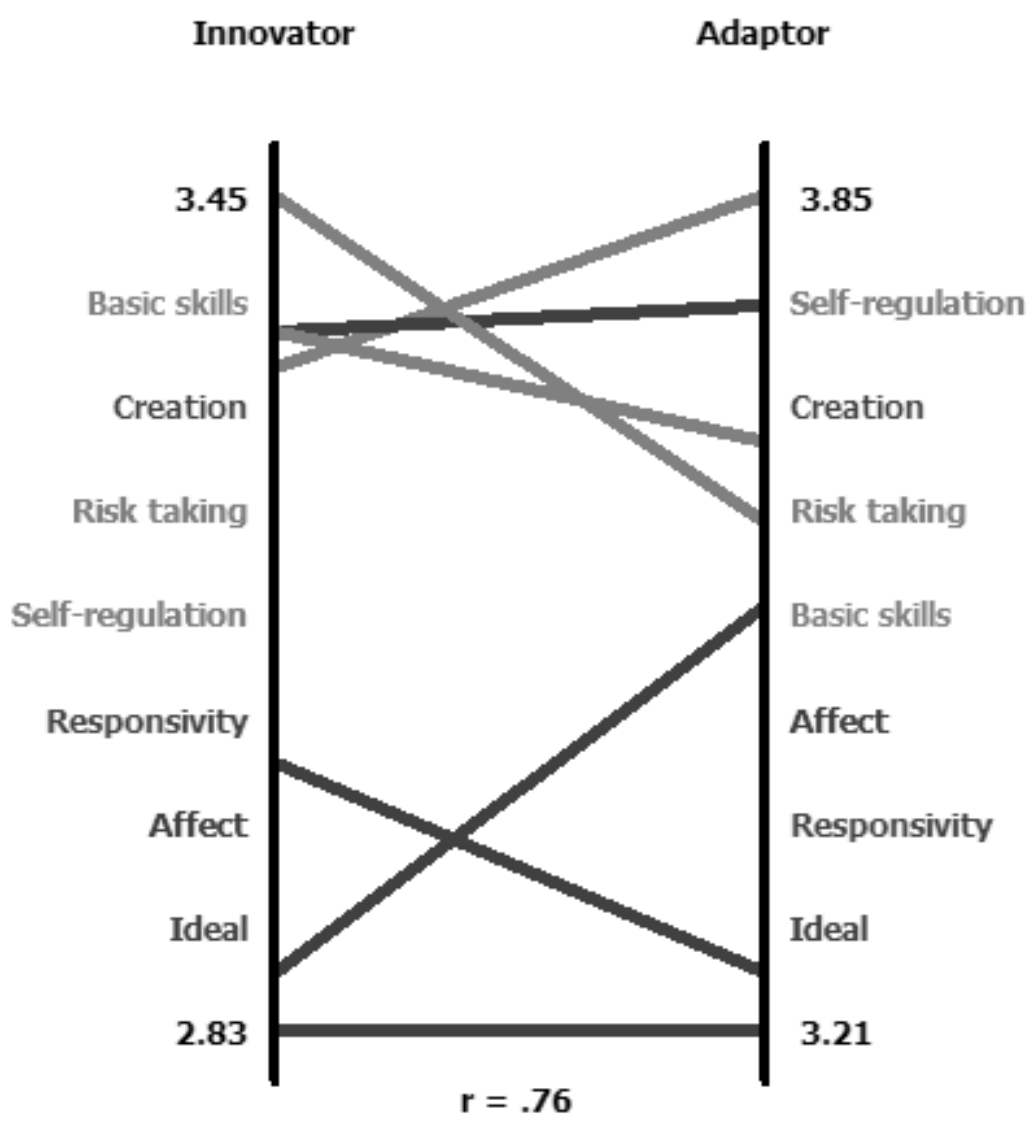

